

Effect of Fiber Coating on Mechanical Properties of Nicalon Fibers and Nicalon-Fiber/SiC Matrix Composites*

\author{
J. P. Singh and D. Singh \\ Energy Technology Division \\ Argonne National Laboratory, Argonne, Illinois 60439
}

and

R. A. Lowden

Metals and Ceramics Division

Oak Ridge National Laboratory

Oak Ridge, Tennessee 37831

December 1993

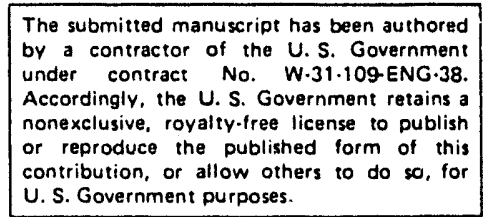

DISCLAIMER

\begin{abstract}
This report was prepared as an account of work sponsored by an agency of the United States Government. Neither the United States Government nor any agency thereof, nor any of their employees, makes any warranty, express or implied, or assumes any legal liability or responsibility for the accuracy, completeness, or usefulness of any information, apparatus, product, or process disclosed, or represents that its use would not infringe privately owned rights. Reference herein to any specific commercial product, process, or service by trade name, trademark, manufacturer, or otherwise does not necessarily constitute or imply its endorsement, recommendation, or favoring by the United States Government or any agency thereof. The views and opinions of authors expressed herein do not necessarily state or reflect those of the United States Government or any agency thereof.
\end{abstract}

Presented at 18th Annual Confere ice on Composites and Advanced Ceramics, American Ceramic Society, Cocra Beach, Florida, January 9-14, 1994.

*Work supported by U.S. Department of Energy, Office of Industrial Technology, Energy Efficiency and Renewable Energy, under Contract W-31-109-Eng-38. 


\title{
Effect of Fiber Coating on Mechanical Properties of Nicalon Fibers and Nicalon-Fiber/SiC Matrix Composites
}

\author{
J. P. Singh and D. Singh \\ Energy Technology Division \\ Argonne National Laboratory, Argonne, Il 60439
}

\author{
R. A. Lowden \\ Metals and Ceramics Division \\ Oak Ridge National Laboratory \\ Oak Ridge, Tennessee 37831
}

\begin{abstract}
The effect of fiber-coating thickness on retained in-situ fiber strength and the resulting mechanical properties of composites was investigated. Flexure tests in a four-point-bend mode were used to evaluate ultimate strength and work-of-fracture of the composites with various fiber-coating thicknesses. Retained in-situ fiber strength in the fractured composites was evaluated by fractographic techniques. Retained in-situ fiber strength, ultimate strength, and work-of-fracture of the composites increased with increasing fiber-coating thickness, reaching a peak value at a coating thickness of $\approx 0.3 \mu \mathrm{m}$. Further increases in coating thickness did not improve the mechanical properties of either the fibers or the composites. A direct correlation between retained in-situ fiber strength and mechanical properties of the composites suggests that retained in-situ fiber strength has a significant influence on the mechanical properties of composites.
\end{abstract}

\section{Introduction}

Continuous-fiber-reinforced ceramic matrix composites are becoming increasingly important for structural applications because of their improved flaw tolerance, large work of fracture, and noncatastrophic mode of failure. ${ }^{1-3}$ Fracture behavior of fiber-reinforced ceramic composites is strongly influenced by the mechanical properties of reinforcing fibers and matrix, fiber/matrix interfacial characteristics, and residual stresses arising from thermal expansion mismatch of fibers and matrix. In order to produce composites with high toughness, it is essential to obtain optimal fiber/matrix interfacial characteristics and high fiber strength. 4 Optimal fiber/matrix bond strength will lead to debonding and subsequent fiber sliding during fracture of composites. This results in substantial dissipation of elastic energy and hence improved fracture toughness. Interfacial characteristics can be tailored by appropriately coating the fiber surfaces.

Strength of reinforcing fibers is critical because once a matrix crack is initiated and extended, load is transferred from the matrix to the fibers in the wake of the crack. 
Weak fibers fracture and lead to catastrophic failure of the composite, wherreas strong fibers accommodate the stresses. As observed in a recent study, 5 the amount of fiber pullout, which contributes to the toughening of a composite, is strongly influenced by the mean strength of the reinforcing fibers. Also, the ultimate load-bearing capacity of the composite is determined by fiber strength characteristics. ${ }^{6}$ Because fiber strength is controlled primarily by critical flaws introduced during composite processing and service, application of fiber coatings can significantly decrease fiber damage and increase retained strength.

It is therefore clear that fiber coatings play an important role in establishing interfacial characteristics and fiber strength which are important parameters for the design and development of fiber-reinforced ceramic matrix composites with superior mechanical properties. In the present study, we have evaluated the effects of fiber coating on flaw generation, retained fiber strength, and resulting mechanical properties of chemical-vapor-infiltrated Nicalon fiber-reinforced SiC matrix composites.

\section{Experimental Procedure}

Seven sets of Nicalon-fiber-reinforced SiC matrix composites with approximately 42 vol.\% fiber reinforcements were fabricated at Oak Ridge National Laboratory by densifying multiple layers of Nicalon mats stacked in a graphite die. Each set has a different carbon coating thickness ranging from 0 to $1.25 \mu \mathrm{m}$. Table 1 lists the specimen identification numbers and respective fiber-coating thicknesses. Chemical vapor infiltration (CVI), under forced conditions of thermal and pressure gradients, was used to densify the preforms with $\mathrm{SiC}$. The resulting composites were nearly $90 \%$ dense. Details of composite specimen fabrication are described elsewhere. 7,8

The composites were fractured in a four-point-bend mode on the universal testing system $^{\dagger}$. Inner and outer loading spans were 15 and $30 \mathrm{~mm}$, respectively. Typical dimensions of the flexure bar specimens were $3 \times 4 \times 32 \mathrm{~mm}$. Flexure tests were conducted at a loading rate of $1.27 \mathrm{~mm} / \mathrm{min}$ under ambient conditions.

Figure 1 shows a typical load-displacement plot obtained during flexural testing of composites with coated fibers. The first matrix cracking stress was determined from the load at which the first deviation from the linear variation in the load vs. displacement plots was observed. Ultimate stress was determined from the peak load value. In addition, composite work-of-fracture (WOF) was estimated from the area under the load-specimen displacement plots normalized on the basis of unit cross-sectional area of the fractured composites. True specimen displacement was obtained by subtracting system displacement from total displacement. System displacement was determined by measuring system compliance with a stiff alumina piece.

†Model 4505, Instron Corp., Canton, MA. 
Table 1. Fiber Coating Thicknesses of CVI SiC/SiC Composites

\begin{tabular}{|c|c|}
\hline Sinple ID & $\begin{array}{c}\text { Coating Thickness } \\
(\mu \mathrm{m})\end{array}$ \\
\hline 571 & 0.0 \\
\hline 526 & 0.03 \\
\hline 522 & 0.06 \\
\hline 538 & 0.13 \\
\hline 524 & 0.27 \\
\hline 549 & 0.61 \\
\hline 521 & 1.25 \\
\hline
\end{tabular}

Fractured composite specimens were examined on a scanning electron microscope $\$$ (SEM) to locate the failure origin and establish the associated characteristic fracture surface morphology of the fibers to estimate in-situ fiber strength.

\section{Results and Discussion}

Figure 2 shows ultimate strength as a function of fiber-coating thickness. The observed variations for the two cases are similar. Ultimate strength increases with coating thickness, reaching a peak value of $380 \mathrm{MPa}$ at $\approx 0.2-0.6 \mu \mathrm{m}$ coating. Further increases in coating thickness do not significantly improve ultimate strength.

Work-of-fracture (WOF) as a function of coating thickness is shown in Fig. 3. The WOF increases rapidly with fiber-coating thickness, reaching a peak of $1.92 \times 10^{4}$

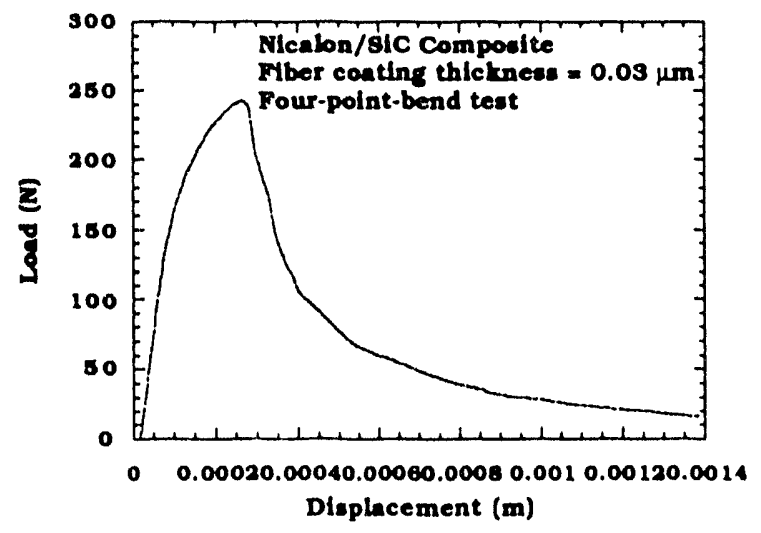

Figure 1. Typical Load-Displacement Plot for Composites with Coated Fibers.

§Model JXA-840A, JEOL Co., Ltd., Tokyo, Japan. 


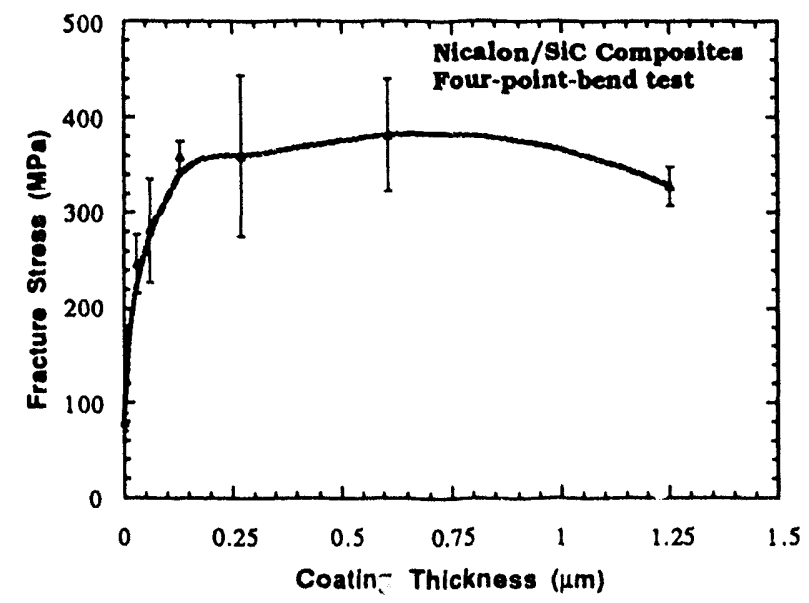

Figure 2. Measured Variation of Ultimate Strength as a Function of Fiber Coating Thickness.

$\mathrm{N}-\mathrm{m} / \mathrm{m}^{2}$ at a thickness of approximately $0.13-0.27 \mu \mathrm{m}$. Values did not change significantly with further increases in coating thickness.

SEM investigation on the fracture surfaces of composites reinforced with fibers with and without carbon coatings revealed differences in their fracture surface morphology, as shown in Fig. 4. The fracture surface shows brittle failure without any fiber pullout in composites with no fiber coating (Fig. 4a). On the other hand, substantial fiber pullout was seen in composites with coated fibers (Fig. 4b). These observations are consistent with load-displacement behavior for the two types of composites. In the coated fiber-reinforced composites, there was gradual decrease in load after the peak load was reached, as shown in Fig. 1. On the other hand, in the uncoated fiber-reinforced composites, there was an instantaneous drop at the peak load.

SEM was also used for fractographic evaluation to estimate in-situ fiber strengths. Specifically, critical flaws and the associated characteristic fracture markings were identified. In-situ fiber strength in the composites was evaluated from measurements of these characteristic markings. Typical fracture surface of a fiber in a Nicalon-fiber-reinforced $\mathrm{SiC}$ composite, tested in the four-point-bend mode, is shown in Fig. 5. Characteristic features associated with brittle failure, such as mirror (a smooth region around the fracture origin) and hackle (a region of multiple fracture planes), are clearly observable on the surface of fractured fibers. SEM investigation showed that most fibers failed from defects or flaws at the fiber surface. 


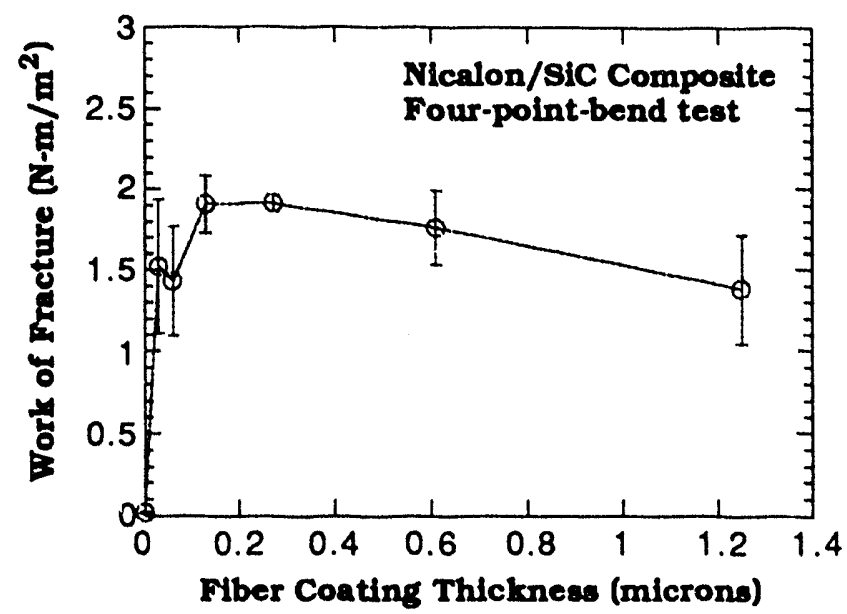

Figure 3. Measured Variation of Work-of-Fracture as a Function of Fiber-Coating Thickness.

It is well known that for glasses and veramics, such fracture surface features as mirror radii can be correlated to tensile strength through the empirical relationship: $: 9,10$

$$
\sigma_{\mathrm{f}} \sqrt{\mathrm{r}_{\mathrm{m}}}=\mathrm{A}_{\mathrm{m}}
$$

where $r_{m}$ represents the mirror radii, $\sigma_{f}$ is the tensile strength, and $A_{m}$ is the mirror constant, which is related to the fracture toughness of the material. In the present study, $A_{m}$ is taken as $3.5 \mathrm{MPam}^{1 / 2}$, following the work of Thouless et al..$^{5}$ Strengths of more than 30 Nicalon fibers for each set of composite specimens were determined by measuring their fracture mirror radii and using Eq. 1 .

The strength distribution for fibers in the composites can be described using the Weibull function given by:

$$
F(\sigma)=1-\exp \left[-\left(\frac{\sigma}{\sigma_{0}}\right)^{m}\right]
$$

In Eq. 2, $\mathrm{F}$ is the fracture probability at a given stress $\sigma, \mathrm{m}$ is the Weibull modulus that characterizes the flaw size distribution in fibers, and $\sigma_{0}$ is the scale parameter signifying a characteristic strength value of the fibers. 

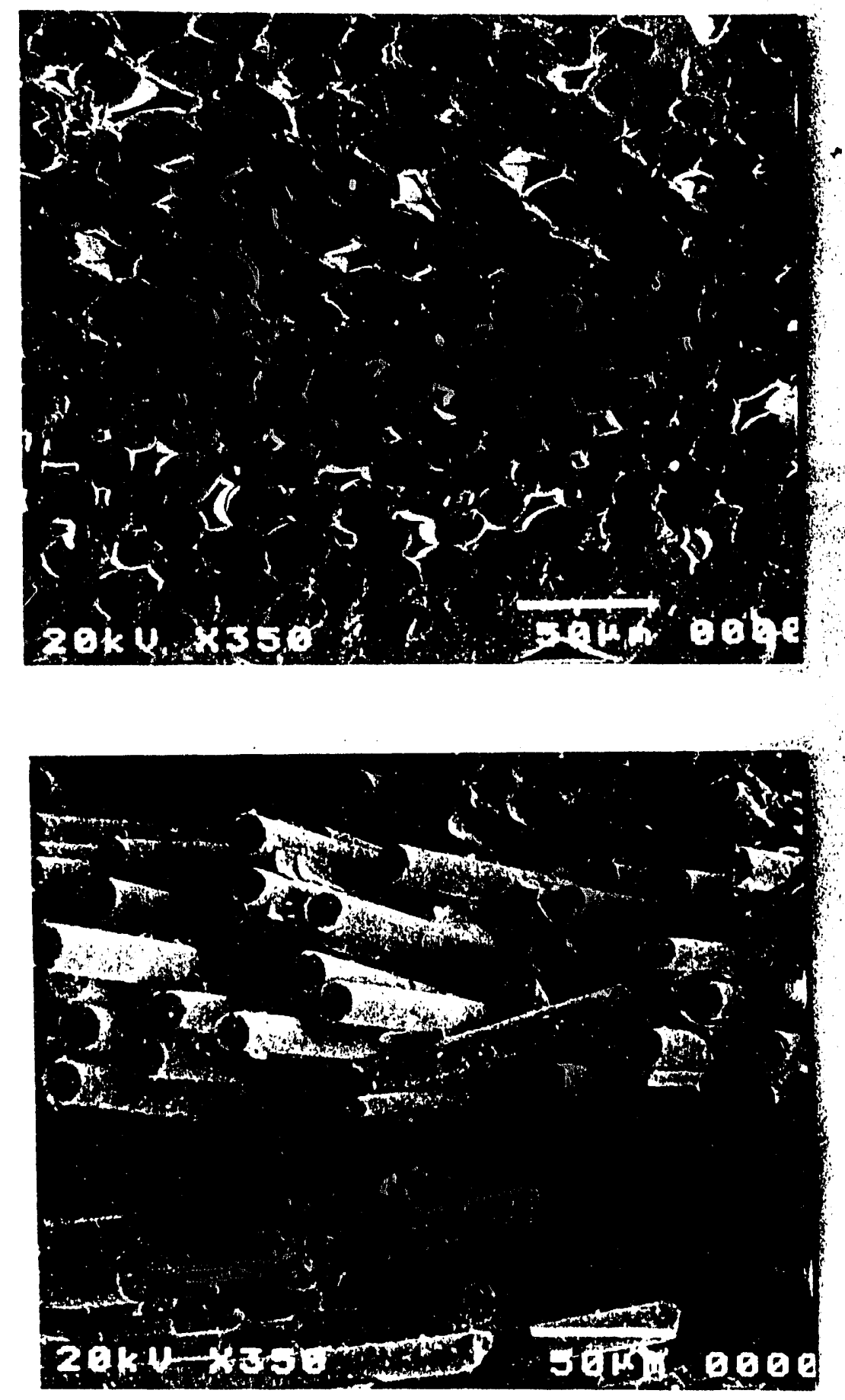

Figure 4 Typical Fracture Surface of Composites Reinforced With (a) Uncoated Fibers and (b) Coated Fibers 


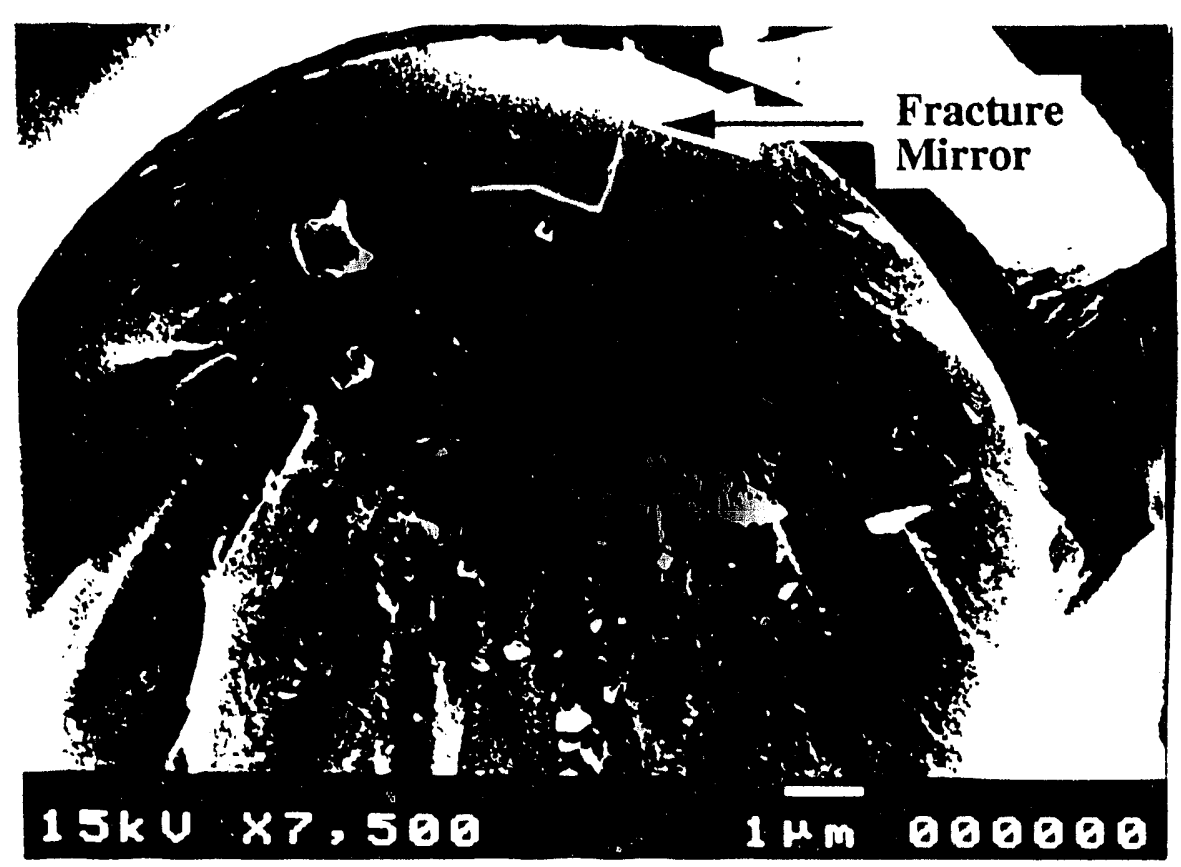

Figure 5. Micrograph Showing Surface Morphology of Fractured Fiber in Composite.

Figure 6 shows in-situ fiber strength as a function of coating thickness. The measured scale parameters depend on gage length, which is approximately equal to the fiber pullout lengths. An evaluation of fiber pullout lengths indicated no significant difference as a function of fiber coating thickness. Therefore, no additional modification to account for variation in pullout length was needed. It can be clearly seen in Fig. 6 that fiber strength initially increases with coating thickness and reaches a peak value at a coating thickness of $-0.13-0.6 \mu \mathrm{m}$. Further increases in coating thickness have no significant effects on fiber strength. It is believed that the initial increase in strength is due to fiber protection by coating, which minimizes fiber surface damage during processing and fabrication. Further increases in coating thickness do not increase the effectiveness of coating in protecting fiber damage. This result has very important implications for determining optimal fibercoating parameters and composite processing.

A comparison of Figs. 3 and 4 with Fig. 5 shows a direct correlation between in situ-fiber strength and ultimate strength and WOF of the composites with various coating thicknesses. This suggests that in-situ fiber strength has a significant influence on the ultimate strength and WOF of the composites. In addition, fiber coating may also be partly involved in improved fiber/matrix interfacial characteristics, leading to the observed increase in both ultimate strength and WOF. 


\section{Conclusions}

1. Processing-induced damage of Nicalon fibers was minimized by coating the fibers with carbon. This resulted in a corresponding increase in retained insitu strength of the fibers during composite processing.

2. Mechanical properties (ultimate strength and work of fracture) of the composites increased with increasing fiber-coating thickness up to a thickness of $\sim 0.3 \mu \mathrm{m}$. Further increases in coating thickness had no significant effects on mechanical properties, indicating an optimal coating thickness for processing.

3. Dependence of in-situ fiber strength, ultimate strength, and work of fracture on fiber-coating thickness suggests a direct correlation bet ween retained insitu fiber strength and resulting mechanical properties.

4. Increased ultimate strength and work of fracture with increasing fiber-coating thickness may also be partly due to improved fiber/matrix interfacial characteristics.

\section{Acknowledgments}

This work is supported by the U.S. Department of Energy, Office of Industrial Technology, Energy Efficiency and Renewable Energy, under Contract W-31-109-

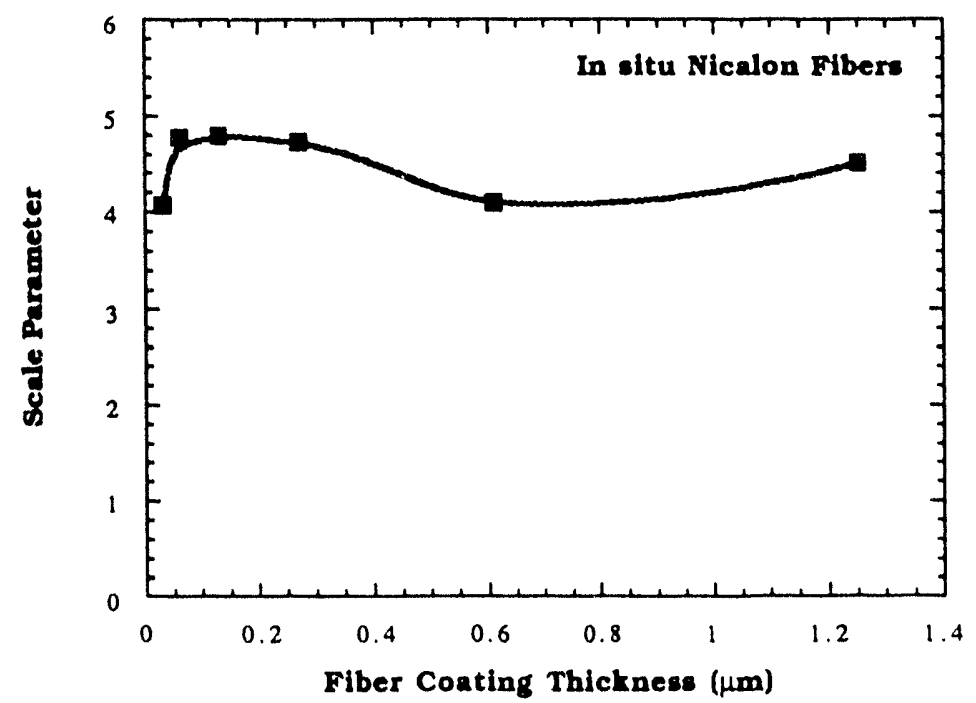

Figure 6. Variation of In-Situ Fiber Strength with Fiber Coating Thickness. 
Eng-38. The authors thank Grant Pollard for providing experimental assistance.

\section{References}

1. D. B. Marshall, B. N. Cox, and A. G. Evans, "The Mechanics of Matrix Cracking in Brittle-Matrix Fiber Composite," Acta Metall., 33 [11] 2013 -2021 (1985).

2. D. B. Marshall and A. G. Evans, "Failure Mechanisms in Ceramic-Fiber / Ceramic Matrix Composites," J. Am. Ceram. Soc., 68 [5] 225-231 (1985).

3. J. Aveston, G. A. Cooper, and A. Kelly, "Single and Multiple Fracture," pp. 15-26, in The Properties of Fiber Composites, Conf. Proc. of the National Physical Laboratory, IPC Science and Technology Press Ltd., Surrey, England, 1971.

4. A. G. Evans and D. B. Marshall, "The Mechanical Behavior of Ceramic Matrix Composites," Overview No. 85, Acta Metall., 37 [10] 2567-2583 (1989).

5. M. D. Thouless, O. Sbaizero, L. S. Sigl, and A. G. Evans, "Effect of Interface Mechanical Properties on Pullout in a SiC-Fiber-Reinforced Lithium Alu- minum Silicate Glass Ceramic," J. Am. Ceram. Soc. 72 [4] 525532 (1989).

6. T. Mah, M. G. Mendiratta, A. P. Katz, R. Ruh, and K. S. Mazdiyasni, "Room Temperature Mechanical Behavior of Fiber-Reinforced Ceramic Matrix Composites," J. Am. Ceram. Soc., 68 [1] C-27 - C-30 (1985).

7. D. P. Stinton, A. J. Caputo, and R. A. Lowden, "Synthesis of FiberReinforced SiC Composites by Chemical Vapor Infiltration," Am. Ceram. Soc. Bull., 65 [2] 347-350 (1986).

8. D. P. Stinton, T. M. Bessman, and R. A. Lowden, "Advanced Ceramics by Chemical Vapor Deposition Techniques," Am. Ceram. Soc. Bull., 67 [2] 350-355 (1988).

9. H. P. Kirchner and R. M. Gruver, "Fracture Mirror in Alumina Ceramics," Phil. Mag. 27 1433-1446 (1973).

10. J. J. Mecholsky, S. W. Freiman, and R. W. Rice, "Fracture Surface Analysis of Ceramics," J. Mater. Sci. 11 1310-1319 (1976). 
. 